\title{
Quantification of left ventricular ejection fraction using through-time radial GRAPPA for real-time imaging
}

\author{
Vidya Nadig ${ }^{1 *}$, Victoria Yeh ${ }^{2}$, Vikas Gulani ${ }^{3,4}$, Robert C Gilkeson ${ }^{3}$, Nicole Seiberlich ${ }^{4}$ \\ From 16th Annual SCMR Scientific Sessions \\ San Francisco, CA, USA. 31 January - 3 February 2013
}

\section{Background}

Cardiac MRI requires a steady cardiac rhythm for ECGgating, and multiple breath-holds to minimize respiratory artifacts. By employing a non-Cartesian parallel imaging in form of through-time radial GRAPPA [1], accelerated imaging can be performed with temporal resolutions of $<50$ $\mathrm{ms}$, obviating the need for gating or breath-holding. breath-holding. We tested the hypothesis that volumetric measurements in the LV obtained with the real-time method could replace traditional measurements.

\section{Methods}

A total of 31 subjects (23 patients, 8 volunteers) were scanned on a 1.5T Avanto or 1.5T Espree scanner (Siemens Medical Solutions, Erlangen, Germany) using a combined spine and abdominal receiver array with 12 to 15 channels. The gold-standard cardiac functional examination was performed in a short-axis orientation with ECG gating, requiring 12-16 breathholds with the following parameters: Cartesian bSSFP sequence, TR 31$62 \mathrm{~ms}$, in plane resolution $=1.4-2.6 \mathrm{~mm}^{2}$, slice thickness $=6-8 \mathrm{~mm}$, cardiac phases $=18-30$. The real-time scans (26 calibration frames per slice and accelerated acquisition) were performed immediately following the goldstandard scan with no ECG gating or breath-holding: radial $\mathrm{bSSFP}$ sequence, $\mathrm{TR}=2.64 \mathrm{~ms}$, resolution $=2.3$ $\mathrm{mm}^{2}$, slice thickness $=6-8 \mathrm{~mm}$. A data acceleration factor of $\mathrm{R}=8$ (16 projections for $128 \times 128$ matrix) was used such that the temporal resolution for real-time imaging was $42.2 \mathrm{~ms}$ per image. Calibration data for non-Cartesian GRAPPA reconstruction was acquired without ECG gating or breath-holds. After data collection and reconstruction, the blood volume in the left ventricle was assessed to determine the ESV, EDV, and EF for both methods.

\section{Results}

Bland-Altman analysis [2] was used to analyze the agreement between the two methods. This showed that 30 of the 31 of the EF measurements using traditional breath-hold imaging and the real-time free breathing method were within the $95 \%$ limits of agreement. The mean difference in LVEF between the two methods was $-2 \%$ (breath-hold minus real-time). All 31 measurements of EDV using both methods were within $95 \%$ limits of agreement. The mean difference in EDV between the two methods was $-4 \mathrm{ml}$. 30/ 31 measurements of ESV using both methods were within the 95\% limits of agreement. The mean difference in ESV between the two methods was $2 \mathrm{ml}$. The differences in EF, EDV, and ESV are not clinically significant [3].

\section{Conclusions}

Our results show no significant statistical or clinical difference between volumetric analysis determined using standard breathhold cine imaging and through-time radial GRAPPA. This indicates that standard method can be replaced by the real-time imaging approach which can be used even for patients with arrhythmia or difficulty with breath-holding.

\section{Funding}

This work was funded by Case Western Reserve University/Cleveland Clinic CTSA UL1 RR024989, and NIH/ NIBIB R00EB011527. 


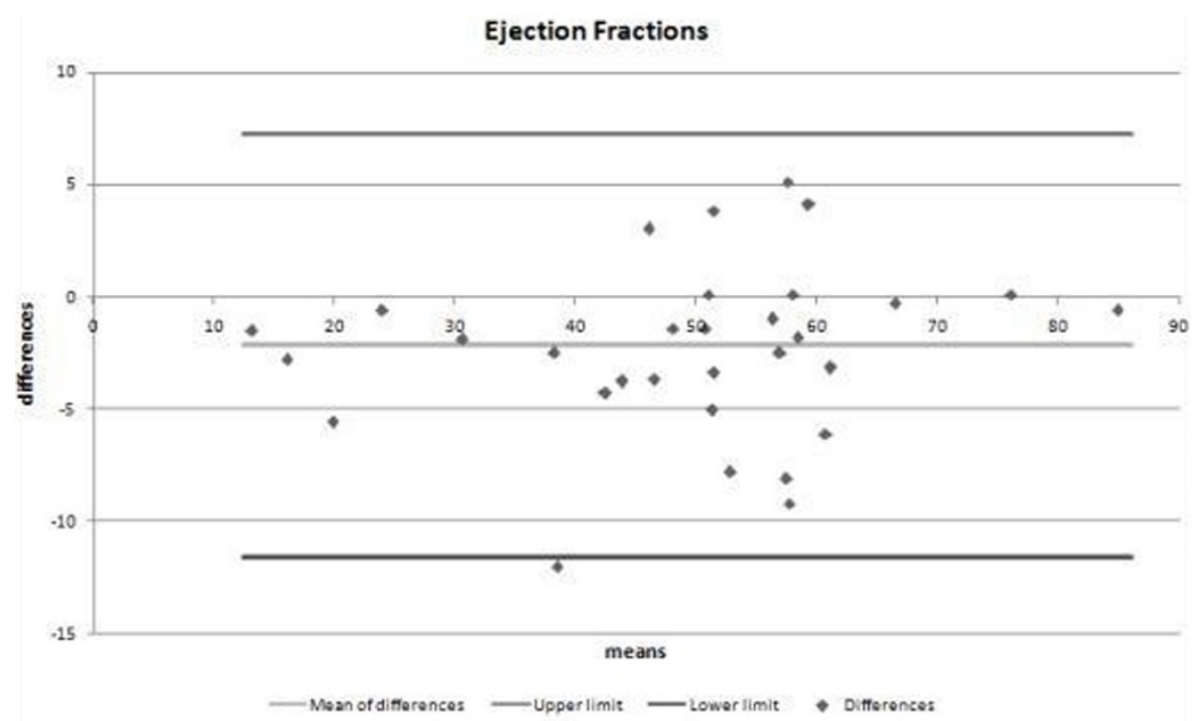

Figure 1 Bland Altman plot of agreement of ejection fractions measured by standard breath-hold technique versus real-time free-breathing technique.

BreathHold Cine

Subject 1

Subject 2

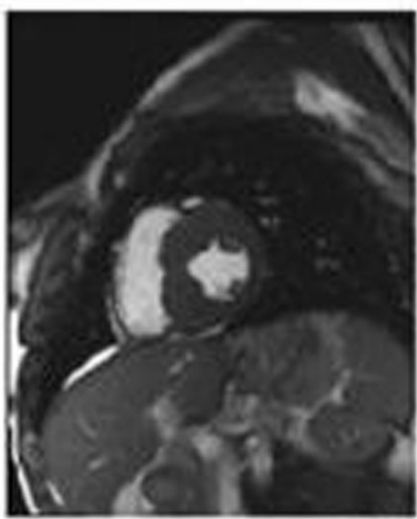

\section{Real-Time Radial GRAPPA}
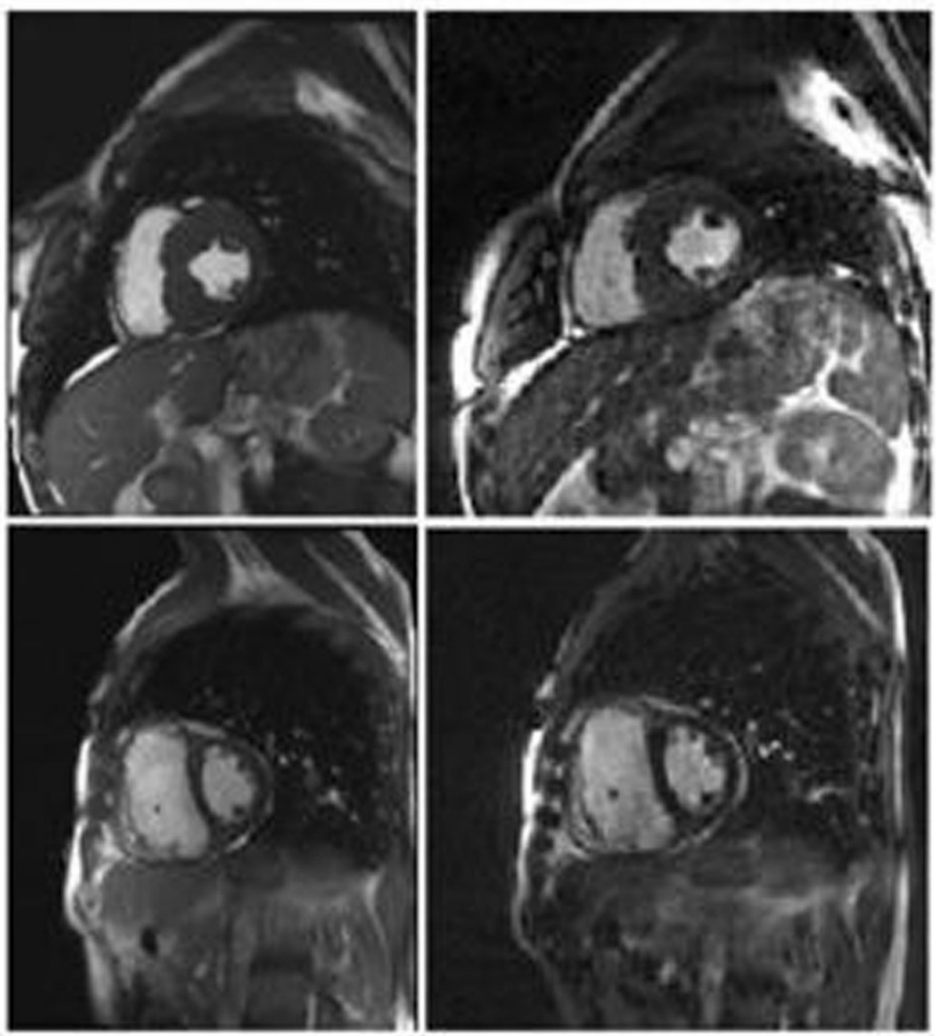

Figure 2 Short axis images of the left ventricle obtained by standard breath-hold method and real-time radial GRAPPA. 


\section{Author details}

${ }^{1}$ Cardiology, Metrohealth Campus of Case Western University, Cleveland, $\mathrm{OH}$, USA. ${ }^{2}$ Case Western University School of Medicine, Cleveland, OH, USA.

${ }^{3}$ Radiology, University Hospitals of Cleveland, Cleveland, OH, USA.

${ }^{4}$ Biomedical Engineering, Case Western University School of Medicine,

Cleveland, OH, USA.

Published: 30 January 2013

\section{References}

1. Seiberlich N, et al:. MRM 2011, 65(2):492-505.

2. Altman DG, et al:. The Statistician 1983, 32(3):307-317.

3. Pattynama PM, et al: . Radiology 1993, 187:261-8.

doi:10.1186/1532-429X-15-S1-P45

Cite this article as: Nadig et al:: Quantification of left ventricular ejection fraction using through-time radial GRAPPA for real-time imaging.

Journal of Cardiovascular Magnetic Resonance 2013 15(Suppl 1):P45.

Submit your next manuscript to BioMed Central and take full advantage of:

- Convenient online submission

- Thorough peer review

- No space constraints or color figure charges

- Immediate publication on acceptance

- Inclusion in PubMed, CAS, Scopus and Google Scholar

- Research which is freely available for redistribution

Submit your manuscript at www.biomedcentral.com/submit
() Biomed Central 